Review

\title{
The Importance of Rapport in Hypnotic Clinical Practice
}

Consuelo C. Casula *

Past president of the European Society of Hypnosis, Board member of the Italian Society of Hypnosis, Via Ariberto 3, Milan, Italy; E-Mail: consuelocasula@gmail.com

* Correspondence: Consuelo C. Casula; E-Mail: consuelocasula@gmail.com

Academic Editor: Giuseppe De Benedittis

Special Issue: Hypnosis: from Neural Mechanisms to Clinical Practice

OBM Integrative and Complementary Medicine

2020, volume 5 , issue 1

doi:10.21926/obm.icm.2001010
Received: January 18, 2020

Accepted: February 14, 2020

Published: February 27, 2020

\section{Abstract}

This article is based on the assumption that the therapist's focused attention, open awareness and kind intention are the basic ingredients for creating a relationship of trust with the patient from the first session. He also stresses that when the attention of a genuine therapist, without prejudice or judgment, is centered on how the patient expresses $\mathrm{him} /$ herself and on the contents $\mathrm{s} /$ he proposes, the patient relies more easily on the competent care of the therapist. The author argues that to empower patients it is essential to accept their vulnerability, awaken hidden resources and define realistic therapeutic goals. In this way, each session focuses on the perceptual, cognitive, emotional and behavioral changes that the patient can undertake during the session and implement after the session, by himself or herself. Through the presentation of some cases, the article shows the importance of concentrating the patient's attention in the present moment with the resources $\mathrm{s} /$ he has in his/her current life, from which to observe significant episodes from the past. The revision of the past from the point of view of the present, which is the future of the past, helps the patient to observe what happened with different perceptions, thoughts and emotions, thus reformulating his representative memory of what happened.

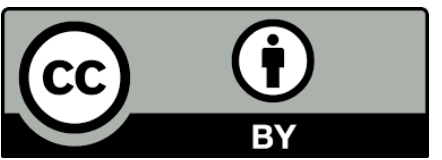

(C) 2019 by the author. This is an open access article distributed under the conditions of the Creative Commons by Attribution License, which permits unrestricted use, distribution, and reproduction in any medium or format, provided the original work is correctly cited. 
The article proposes the transcription of a typical induction that the author usually uses to establish a relationship based on a secure attachment to evoke a feeling of calm and trust in the patient. It also provides the transcription of several inductions used during some highlights of a therapy session of the selected cases. Each case and each induction has been chosen to show how attachment theory concepts have been used in hypnotic practice as an indispensable tool for building and maintaining a therapeutic relationship based on mutual trust.

\section{Keywords}

Rapport; attachment; trust; hypnotic inductions

The objective of this article is to stimulate reflection on the importance of developing rapport in hypnotic clinical practice. A combination of attachment theory with several hypnotic techniques such as utilization and reframing has been proposed in this article.

This article starts with some questions such as "Is rapport a predictor of therapeutic success?", "Is rapport the guardian of the quality of the therapeutic process?", and "Is rapport a guarantee of the trust between therapist and patient?". This article illustrates building and maintaining a therapeutic alliance based on "focused attention, open awareness, and kind intention" in order to develop a relationship of mutual trust and reciprocal understanding [1].

Rapport is defined by the author as the unconditional acceptance of patients' vulnerability, the empathic attunement with whom they are and the empowerment of their strengths before defining any therapeutic goal and suggesting any kind of change. Rapport is the perception of the patients experienced while the therapists employ their verbal and analogical communication to connect their conscious and unconscious minds [2].

Based on M. H. Erickson's suggestion, a therapeutic alliance is established, irrespective of patients' behavior, by illustrating them that they are completely accepted as they are. Rapport is when the patient has the feeling of being accepted, understood, and connected, whereby, s/he can develop trust in the therapist and therefore, count on the therapist's care. Rapport facilitates therapists to address any emotion experienced by patients, to reduce their intensity or duration, to calm them during the session, to assist them to improve their executive functions, thereby, mitigating their fear of the future [2].

In this article, three cases are offered to illustrate those points in action.

\section{Building Rapport from the First Session}

Patients seeking therapeutic help are mostly in a vicious circle: they fear to be unable to overcome a past experience, to be incapable of achieving their goals and are unaware of the solution to the problem. This fear indulges in immobilization which again reinforces fear [3].

Restoration of the active and effective defensive responses is achieved by the therapist by interrupting the vicious circle, reinforced by the patient's emotions, such as anger, sadness, guilt, shame [4]. An emotionally corrective experience is offered by the therapists to the patients, 
guiding them to reduce negative feelings and rejuvenate the sense of self-confidence in a world filled with volatility, uncertainty, complexity, and ambiguity [1].

To initiate the first session, it is essential for the patient to comprehend the therapist as competent, genuine, caring, and non-judgemental. The initial acceptance of patients' behavior, followed by their collaborative response, orchestrates the path of therapeutic change paved by the relationship based on trust [2].

Hypnotists, in their first meet, convey one of the main messages to their patients that they are in a safe place where they can awaken their dormant resources. Patients are empowered by the hypnotic therapists to respect and protect their vulnerability, to increase their resources in facing challenges, to connect body and mind, heart, brain, muscle, bones, and to install lasting changes in their emotional and cognitive processes, as well as in their behavior [5].

Hypnotic techniques engage the therapist to collect and calibrate verbal and non-verbal messages sent by the patient. The process of mutual influence develops a bond and maintains a good attunement. The therapists' kind intention, motivation, and commitment to listening/helping/sustaining patients to achieve their well-being in an efficient and effective way bridge the gap between the therapists and the patients.

Rapport in hypnotic clinical settings helps patients to develop the internal locus of control, selfesteem, self-efficacy, independence, and interdependence. Patients are encouraged to depart the land where they have enacted the role of victim and explore a realm where they act as agent, as problem solvers, and improve their ability to use their critical thinking, creative imagination, and planning how to promote evolutive changes $[2,6]$.

At the end of the therapeutic process, patients divert their attention from problematic events of the past to projections of open future, curious to explicitly define their goals, reinforced by their aspirations, motivation, and perseverance [7].

Rapport is mainly built and maintained by nurturing the communication style of the patients. Utilization is nothing more than making good use of what happens during the session and matching what patients bring to therapy: breathing, posture, gestures, body changes, words, metaphors, tone of voice, beliefs, interests, values, and priorities [8, 9]. An important role is also played by the reframing, which is incorporating new and empowering perspective to the patient teaching skills and providing experiences that uplift his/her life [10].

\section{The Role of Hypnosis in Building and Maintaining Rapport}

At the beginning of the session, the consequences of the hypnotic induction are to stabilize and calm patients making them feel seen, safe, protected, calm, and secure. Once the patients realize that they are recognized for what they are, the therapists aid them in shifting their attention to their resources and regaining confidence in their future.

Therapists specialized in hypnosis are conscious regarding the importance of expressing their linguistic competence and verbal fluency. Delivering congruent messages of attunement through their body language and their tone of voice is also essential for treating patients. Eye contact of the hypnotist with the patient along with a pleasant smile, relaxed and soft body posture, warm and gentle gestures are essential in order to provide the patients a comfortable environment and to make them feel that they are acceptable as they are. Voice modulation according to the emotional strings they wish to touch is essential to deal with such patients. The modulation of 
facial expressions of the therapist reflecting congruence with what the patient is narrating is a technique to portray their resonance.

An empathic resonance is established with the patient's narrative through these therapeutic sessions. Empathic resonance means not only feeling what patients feel, but also encompasses their perspective, visualizing through their eyes according to their cognitive schemes, imagining their mental experience, their attributions to what happened, and their representation of the world. Therapists who show attunement, resonance, and willingness to take care of patients' wellbeing, also share the happiness for their achievements [1].

Staying focused on the present therapy helps patients to concentrate on the experience of the session, aware of being in the future of their past and thus relate their story from the point of view of the present, separating the past, present, and future. The patients are asked to retrospect the past incidents that might be related to the current suffering. Unearthing a "problematic episode" that seemed to be the starting point of the suffering of their current life, help them differentiate between past and present.

Furthermore, the therapist invites patients to realize what they learned that they did not know before and that they could not have learned in any other way $[7,11]$.

\section{Rapport Based on Secure Attachment}

A secured bond involving the same attachment patterns studied by John Bowlby [12] is carefully established by the therapist in order to develop and sustain a rapport based on trust. It is important that patients in therapy feel seen, soothed, and safe, like a child with a caregiver. This helps strengthen the sense of security in the patients. They learn to maintain hope and improve their resilience even during adverse situations. [9]

My usual initial induction begins in this way, changing it according to the uniqueness of each patient.

At this moment, you are here in my office and today is ... day, month, year.

This is a safe place for you. With eyes closed you can perceive the luminosity of the room which is subjected to change based on the hide and seek clouds play with the sun; you hear the sound of my voice, the tic-tac of the clock reminding you of the inexorable passing of time. Time passes even if you stay still and do nothing but concentrate on finding a relaxing position. The passing of time is an alarm to remind you that the only place you are going to is the future. You can also smell the fragrance in the room. You may feel a residual taste in your mouth. And now you can start focusing your attention on all the contact points of your body, such as your feet touching the ground, thighs, and bottom on the chair, your back resting on the back of the chair, your arms supported by the arms of the chair, and your hands on your lap. Even with your eyes closed, you can sense my full presence focused on your wellbeing while we are together in this secured place. I just noticed that your breathing is becoming calmer and calmer, and your facial expression is becoming more relaxed so that you experience that the more you relax your body the more you relax your mind; the more you relax your mind the more you relax your body. 
Synchronization with the feelings, thoughts, and body language responses of the patients with the therapist generate a sense of security among the patients. They feel that they are seen, heard, held, and healed by a therapist. Distressed patients learn to calm down when they realize their therapist is able to transmit calm. Thus they feel they are protected from danger, kept safe, and cared for by their therapist, who will educate them on how to soothe themselves.

Right from the beginning the hypnotists try to impose an emotionally corrective experience of secure attachment with the patients, by seeding verbal and non-verbal messages such as "I'm with you in the here and now ..., I'm in tune with you..., You are in a safe place..., I resonate with you..., I understand you..., You can learn now how to calm down..., In this safe place you can recognize that you have all the resources you need at this moment in your life..."

A rapport based on secure attachment helps the therapists to utilize hypnosis to diminish patients' sense of alertness, simultaneously empowering their sense of security and confidence. A safe environment incorporates a sense of protection and fearlessness among patients. This can pave the way to discover the pleasure of exploring a new world full of opportunities, play new games, and cultivate their imagination in creating new projects that can reform their lives.

Here are the three cases.

\subsection{The Case of Monica}

Monica, a 32-year-old woman, is afraid of crickets and does not know what to do when she encounters them. She recently shifted to her newly purchased house with a garden. In her previous condominium apartment, she did not face the problem of crickets. However, now she finds it when she returns home from work. She is very much attached to her new house and the garden. She does not want to indulge in the risk that her fear will ruin her return to home in the evenings when she spends a lot of time hunting for crickets in every corner.

During our first session, I followed a metaphorical model of mine namely "The Five Petals of Identity", useful for discovering strengths and vulnerabilities in each petal, so that a suffering petal can receive help from the others $[7,11]$. The first petal represents the qualities of body identity characterized by gender, age, and physical appearance; the second concerns the power of belonging coming from social identity. The third petal deals with a sense of self-efficacy attributed to professional identity. The fourth signifies our transcendent spiritual parts connected to virtues and values, morals and ethics. The fifth embodies secrets regarding every aspect of the previous petals.

After reaching the state of trance post-induction, I started sending these therapeutic suggestions to Monica.

At this moment you can focus your attention on the five petals of your identity. You can start with becoming aware of the body you've lived in since your birth. You might also recall all changes that have occurred since you were born until today since you weighed a few kilos and were a few centimeters long until your current weight and height.

Just as you can remember the changes that have taken place in your social relationships, from the time you were mainly the daughter of your parents to the time you started going to school and met friends, from primary school to secondary school to university where you contacted people and made new 
friends. Over the years, your knowledge has also undergone modification, improvement, and refinement. You now know how many things you have learned that have changed your way of thinking and observing the world. Until you entered the world of work, first with one role, then with another role, then with another role. You are now aware of the alterations you went through in your job and all the skills you have improved day by day, week by week, month by month, year by year.

Following the five petals metaphoric model, I asked Monica to recollect all the changes she came across in her life from the anagraphical, social, and professional perspectives. I modulated my voice to underline the word change. I went on to say:

With this awareness now imagine being in front of a cricket and perceive what you see, what you hear, what you feel, what you think, and what you do. You can now divert your attention to what you are thinking right now, knowing that thoughts are only thoughts, they come and go. You can now move your attention to what you are feeling right now, also knowing that emotions are only emotions, they came and go. Now that you have explored your sensations, thoughts, and feelings you can start being curious about noticing how you perceive yourself in the presence of a cricket. With this awareness now imagine being in front of a cricket and notice that something has changed in your way of seeing, thinking, and feeling and that you are capable of doing something different.

At the end of the induction, Monica told me that she had experienced the differences between her and a cricket and sensed a calm which motivated self-efficacy. At the conclusion of the first meeting, Monica was keen for a second session, which we agreed would be scheduled three weeks from the first one.

In our second meeting, Monica told me that she was no longer afraid of crickets. She was able to handle them calmly and efficiently. So I was curious to know why she came back. She replied that she was in search of the origin of the fear.

The second hypnotic intervention aimed at bringing Monica back to her past to find the episode of the first time she experienced she was afraid of crickets. After the initial induction, I said:

Now that you are here and now in this safe place, be aware of all the resources you have and when you are ready, leave your unconscious mind free to select the oldest memory connected with that fear of crickets. After discovering that episode, when you are ready, you can open your eyes and tell me what I need to know to continue to help you.

Monica opened her defocused eyes and told me that she had gone back to when she was a little girl (about 3-4 years old), playing in the garden of her parent's house and at one point, a cricket jumped on her. She screamed in fear, drawing her mother's attention. When the mother went to the garden and realized that her daughter had been attacked by a cricket, she invited Monica to go inside the house, telling her that she would take care of the insect. There were no further comments from her mother.

Once I received this information, I reminded Monica of the resources she had discovered during the first session. I, then, recommended her to go back to the little Monica to teach her what she now knew and help her manage the emotions of the past. 
With the full awareness that you are in the future of what has happened in your past be ready to go back now, dressed as you are today to help little Monica of a long time ago, when she was only 3-4 years old, her body was the body of a 3-4-year-old girl, her experience was of a 3-4-year-old girl, her knowledge was of a 3-4-year-old girl. The woman who is in front of me right now is 29 years old and has a body of a 29-year-old, knowledge and experiences of a 29-year-old woman. Now that you are in the future of what happened to little Monica I ask you to go back to her and talk to her. You are the only person who knows what little Monica would have needed at that moment. You are the only person who knows what little Monica would have liked to hear and now you can tell her.

After the induction, Monica told me that she had taught little Monica to calm down and to behave accordingly.

The experiences she gathered from the retrospective view of the childhood memory, Monica acquired two types of awareness: the one that kept implicit traces of her child self in the past and the other that recognized her adult resources in the present. She was a little girl whose mother was unable to teach her the difference between fright and fear and pursue a simple reality test: you are stronger and bigger than a small cricket.

The episode that emerged in Monica's explicit memory belonged to an implicit memory layer that had restored in her brain the primary imprint of a fearful experience. The hypnotic interventions assisted Monica to transform her implicit memory contained in sensations, emotions, images, thoughts, and behavior provoked by the old fear of the cricket into an explicit narration where she sees herself able to treat the harmless insect in an adult and efficient manner.

\subsection{The Case of Elena}

Elena, a seventy-year-old, came to therapy encouraged by a former patient of mine who was anxious about Elena's depression and her desire to die. In six months Elena lost her brother and a close friend, which justified her depression. Were there any reasons to want to die? Elena isolated herself, confined herself in her house and was unwilling to carry out the normal daily activities. Despite being full of resources, she felt she did not deserve to live. Termination of her life seemed to be the best solution for Elena.

During our first session, her desperation and a lack of confidence in the therapy provoked me to apply mainly conversational hypnosis. The development of a trusting alliance was the main objective for the first session so that she could attend the second session with the anticipation that she would be benefitted from our meetings. For this reason, I watered the roots of hope by inviting her to remember her past life when she had bounced back from depression by awakening the resources required to deal with her present situation. At the end of the first session, she was convinced to see me for another encounter.

During the second session, I asked her to freely talk about her desire to die. She shared her life story regarding her family where she was neglected by both her parents because their attention and expectations were toward her brother. For the purpose of this article, only an emblematic example of her narration has been selected. 
Her parents were ignorant regarding her studies, though she was a good student. Elena was inclined toward culture, literature, and art. She got a job to support her college expenses and when she finally graduated she told them, "Today I graduated cum laude". The father's first answer was, "What a pity your brother left college and did not graduate." Not even her mother uttered words of satisfaction, pride or congratulations. Despite the discriminatory and unfair attitude of her parents, Elena developed the ability to recover and continue to love them and she looked after them until their deaths. She also took care of her brother until his death. After the death of her brother, however, she felt guilty.

She was of the opinion that, if her parents had still been alive, they would have preferred her death to her brother's. Thus I decided to work on her guilt.

After eliciting a hypnotic state, I suggested to Elena:

Let your unconscious mind remind you of some episodes of your life with your brother. Go back to the time when you wanted to study simply because you loved to spend your time reading books of literature, of art, of history, while your brother loved doing different things. Now is the time to be true to yourself and explore carefully if you did anything wrong that refrained your brother from studying. Be honest and explore now if you did anything wrong that prevented him from studying instead of doing what he liked best.

I started my induction by highlighting the differences between her and her brother regarding studying, to let her experience that she had not committed any sin. Then I shifted her attention to her brother's last period of life.

Now go back to the period when your brother was ill and you took good care of him. Go there with him, talk to him, spend all the time you need to tell your brother how much you loved him. And you can also listen to what your brother is willing to tell you before passing away.

With these suggestions, I wanted Elena to realize that she had done her best to look after her brother and helped him to die in peace. Since she loves culture, I proceeded with the Greek myth of Admetus, Alcestis, and Apollo, as a particularly useful metaphor at this moment.

Let me now tell you the Greek story of Admetus, Alcestis, and Apollo that you may already know. The God Apollo expressed gratitude toward Admetus because he had hosted God during his exile. When Apollo learned that Admetus was to die, God gave him one more day of life to allow him to find someone willing to die in his place. Neither his father nor his mother wished to die in his place: the only one who accepted the exchange was his wife Alcestis. When Alcestis reached the underworld, God Thanatus was so impressed by her generosity and love that he sent her back to earth to live. You know that these things happen only in Greek mythology. In reality, nobody can bargain with any God for the life or death of someone else. Even though you would like to accept death on behalf of your brother, you know that this was impossible. Your brother accepted his fate to die before you, so you have to accept your fate to live longer than him.

This was a cultural way to remind her that she was unable to prevent the death of her brother. So she need not be guilty in this matter. At the end of the second session, Elena fixed another appointment. 
During our third session, we shifted attention to the distressing demise of her friend. This death was also associated with guilt: the two friends shared many activities. They sang in a choir, were part of a group of creative reading and writing, visited painting and sculpture lessons, and to films and exhibitions. As her friend was unable to participate in these events, Elena developed the limiting belief that, by continuing to do alone what she previously had done with her friend, might end up in deceiving her friend.

After the initial induction, I told Elena

Now you can go back to the days when you and your friend spent your time together, singing in the choir, going to creative writing and other activities that you liked so much. Be there with her now and enjoy doing what you liked best. Imagine you are with your friend and you are talking to her as you used to do when you were together. Now that you feel her presence here and now, you can also sense her presence next time you sing in the choir, next time you paint or sculpt, next time you write or read a poem. You know that even though she is not anymore on this earth you can still be with her. Just go inside of you and feel her spiritual presence close to you. Imagine that your friend is happy and grateful that you are still bringing her with you, continuing to carry out the same activities, honoring your friendship. Just imagine having her at your side, continuing to be with her, dedicating her the art and beauty you are surrounded by.

Elena attended two more sessions with the aim to strengthen her resources. In the meantime, she started going back to painting class, singing in the chorus and engaged herself in writing poems. I expressed my sympathetic joy when I came to know that she accepted sketching portraits of children. Having consolidated her new attitude toward life, she realized that she was lucky to be alive. She acknowledged the fact that she would disrespect her friend's memory if she ceases doing what she used to do with her friend. She reached the conclusion that, in order to illustrate her love for her brother and friend and to honor their memory, she had to continue doing what gave meaning to her life.

Hypnosis helped Elena to gain awareness regarding the association between different experiences and integrated them into a coherent story. When she frankly discussed the veiled desire to kill herself, she confessed that it was not what she really wanted. She was looking for a life she deserved to live in her own way, surrounded by justice, art, and beauty.

The induction technique similar to the one with Elena is usually employed for a patient, lamenting the death of a loved one. This can achieve the purpose of integrating the natural phenomenon of life and death and of saying goodbye to the dead person.

Elena's case demonstrated how the hypnotic utilization of her favorite "medicine" - culture, art, and beauty - along with her attachment for the dead loved ones enlightened a new purpose in her life. I moved a "tree trunk" full of guilt to encourage Elena to proceed lighter toward the path of her well-being. Just as the river begins to flow again after the tree trunk, blocking its path, has been eradicated, patients also continue to improve spontaneously when they start integrating problematic memories. 


\subsection{The Case of Marilia}

A 28-year-old girl named Marilia lost both her parents within one month. She was the single child of her parents. The apparently healthy father died suddenly two weeks before her mother, who was suffering from terminal cancer. The shocks induced by these two deaths indulged her to come for treatment. In the first session, Marilia stated that she missed her parents so much that she desired to reach them, as early as possible. Ignoring this veiled threat of suicide, I tried to divert her attention to her body and enquired if she ate and slept regularly. She replied she did not eat, which was not astonishing for me, considering her circumstances. She also told me that she was unable to sleep, which instead I thought needed to be solved.

I, therefore, asked her what abstained her from sleeping. She replied that she felt such a heavy burden on her chest that she was unable to breathe properly.

After eliciting a hypnotic state, I employed the strategy of pain dislocation and told her: Now image it is already the end of today (naming the precise day, month, and year) and prepare to go to bed. Just do the usual ritual of taking off your clothes worn today, putting away the thoughts thought today, ignoring the sensations felt today. Get ready to take off everything you do not need to bring to bed to ensure a deep restful night's sleep. When you realize that you have taken off all that you do not need to carry into the sleeping world, feel the weight you said you felt on your chest. With your own times and your own rhythms, now imagine shifting that weight from your chest toward the shoulder and then slowly from the shoulder down your arm, until it reaches the palm of your hand. Now feel the difference in your chest, free of the weight that has now been relocated on the palm of your hand. When you're ready, move that weight from the palm of your hand to the bedside table. Make sure to place it right on your bedside table. It is important to know that when you fall asleep, you are sure that the weight is there, comfortable and quiet, so that the next morning when you wake up, you find it on the bedside table. In this way, when you wake up, you take the weight in your hand and make it move up on your arm until it reaches the shoulder and then, put it back in its old place on the chest.

This induction worked and Marilia reported that she had slept enough when she arrived for the second session. To address the suicidal threat in Marilia, I began my second therapeutic intervention with a direct and provocative question: "Why do you want to kill your parents?" To this question, she replied that they were already dead. I repeated: "I know. If you think you want to die, it's like wanting to kill them a second time. Your death will delete the only proof that they existed on this earth and that they were good parents."

After this explicit reframe, I took advantage of her state of confusion and recommended to her to close her eyes and dive inside herself. I told her:

I know how much you love your parents and how much you miss them. The best way to portray how much you love them and that you continue to love them even though they are no longer here, is to honor the life they gave you. Only if you live a meaningful life, you can show that you really loved them. Now take all the time you need to be with your parents, to talk to them telling them what you 
never told them before and also listen to what they are willing to tell you right now.

The reframing proposed a change of values: if you live a good life, you show that you had good parents who taught you that the most important thing is giving meaning to your own. The communication with her dead parents helped Marilia to keep the connection with them.

\section{Ending Remarks}

Put your sorrow into words.

The grief you keep inside you will whisper in your heart until it breaks.

\section{W. Shakespeare}

Establishment of a relationship of trust with the patient from the first session and not being afraid to ask patients to give words to their pain, help them transform their suffering into a narrated story. This, in turn, aims to develop a distance between the patient and the past incidence. Translating their sorrow into words helps resolve any residual passivity, any guilt for what they think has committed or omitted, any shame for what wrong they think they did or any rancor for what others were not able to do. Illustrating their story with their adult voice also helps patients identify that they are no longer a victim of what happened: they are now empowered by understanding and the lesson they have learned from the past incidence.

When attention goes to the learning process initiated after a problematic event, patients discover that they do not need to dramatize the effect of what happened (Elena's and Marilia's cases), nor trivialize the meaning of it (Monica's case), nor justify the misbehavior of others (Elena's case). Thus they learn to accept the incidence as something that occurred in their past and is part of their story. They also recognize that they are more than their story.

In each person, there is a stratification of pain, some layers are distant, while others are more recent [1]. The pain narrates the patient's story: sometimes bringing limitations, other times conveying resilience. Some pains are part of the memory of the mind (Monica), other pains of the memory of the heart (Elena), and still others of the memory of the body (Marilia) [3, 4, 13] Therapists welcome each pain and each memory, in turn, teaching the patients the art of acceptance of the incidence that cannot be changed and the awareness that, after therapy, they can illuminate their old story with new words, describing new emotions and new thoughts.

A therapeutic alliance developed on a rapport based on attachment and trust established in the first session assists the patients to start perceiving themselves as empowered and legitimized to use their strengths and resources without ignoring their own vulnerability. They change their role from a victim to an agent or person ready to plan for their future, with the full right to live their lives without fear, guilt or shame, because these emotions are not necessary anymore.

The therapeutic work with Monica, Elena, and Marilia showed that the hypnotic induction imposed on them helped them to evaluate the characteristics of the past events, improve their current management and adaptation skills (coping styles), develop their self-regulation, and their ability to calm down. I empowered them by transferring my therapeutic sensitivity into their hands so that they could begin to love themselves and their lives.

Hypnotic induction started with the utilization of the problem confronted by the patient and proceeded with reframing it $[2,8]$. The induction was based on accepting and utilizing what the patients brought to therapy, inviting each of them to identify their vulnerabilities as well as their 
strengths. Placing the past in the past is a way to make peace with what happened and cannot be altered. Placing the past in the past is a way to fully live their present; living the present is their awareness that they are going toward the future they are creating in the present [7].

\section{Acknowledgments}

I thank the different teachers who over the years have taught me how to take care of patients and help them to take care of themselves, and patients for the trust they have shown in relying on my care.

\section{Author Contributions}

Consuelo C. Casula is the only one author.

\section{Funding}

No research.

\section{Competing Interests}

The author has declared that no competing interests exist.

\section{Reference}

1. Siegel D. Aware: The science and practice of presence-The Groundbreaking Meditation Practice: Penguin; 2018.

2. Zeig JK. The induction of hypnosis: An Ericksonian elicitation approach: The Milton H. Erickson Foundation Press; 2014.

3. Porges SW. The polyvagal theory: Neurophysiological foundations of emotions, attachment, communication, and self-regulation (Norton Series on Interpersonal Neurobiology): WW Norton \& Company; 2011.

4. van der Kolk BA. The body keeps the score: Brain, mind, and body in the healing of trauma. New York, NY, US: Viking; 2014. xvi, 443-xvi, 443 p.

5. Yapko MD. Hypnosis and treating depression: Applications in clinical practice: Routledge; 2013.

6. Yapko MD. Essentials of hypnosis: Routledge; 2013.

7. Casula C. La ciotola d'oro. Vivere II Presente. Apprendere Dal Passato. Progettare II Futuro In Terapia Mimesis, Milano. 2017.

8. Zeig J. The virtues of our faults: A key concept of ericksonian therapy. Confluence: The selected papers of Jeffrey K Zeig. 2006; 71-94.

9. Short D, Erickson BA, Klein RE. Hope \& resiliency: Understanding the psychotherapeutic strategies of Milton H Erickson. Carmarthen, UK: Crown House Publishing; 2005.

10. Yapko MD. Trancework: An introduction to the practice of clinical hypnosis: Routledge; 2012.

11. Casula C. La forza della vulnerabilità. Utilizzare la resilienza per superare le avversità: Utilizzare la resilienza per superare le avversità: FrancoAngeli; 2011. 
12. Singh N. A Secure Base: Clinical Applications of Attachment Theory. By John Bowlby. London: Routledge. 1988. 180 pp.f 8.95 (pb). Br J Psychiatry. 1988; 153: 721-721.

13. Levine PA. In an unspoken voice: How the body releases trauma and restores goodness: North Atlantic Books; 2010.

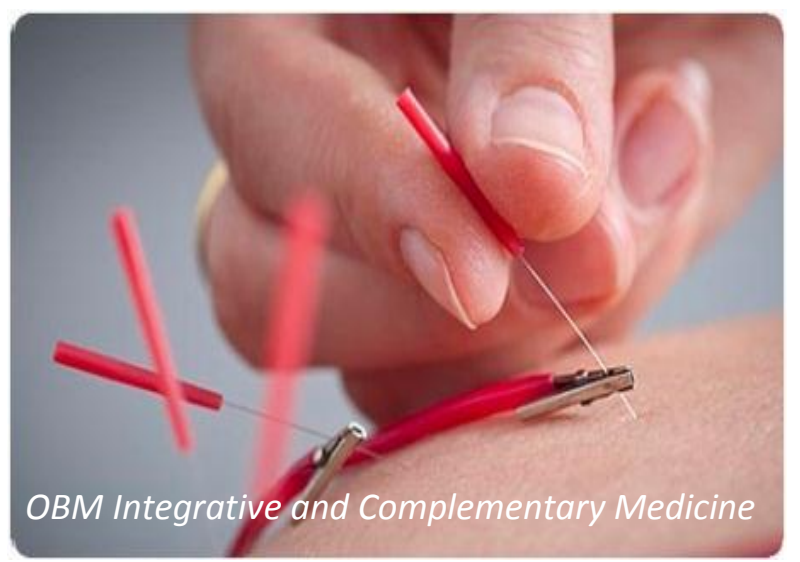

Enjoy OBM Integrative and Complementary Medicine by:

1. Submitting a manuscript

2. Joining in volunteer reviewer bank

3. Joining Editorial Board

4. Guest editing a special issue

For more details, please visit:

http://www.lidsen.com/journals/icm 